\title{
Comparison between Reducibilities of Columnar Silico-ferrite of Calcium and Aluminum (SFCA) Covered with Slag and Acicular SFCA with Fine Pores
}

\author{
Boyuan CAI, ${ }^{1) *}$ Takashi WATANABE, ${ }^{2)}$ Chikashi KAMIJO, ${ }^{3)}$ Masahiro SUSA $^{2)}$ and Miyuki HAYASHI ${ }^{2)}$ \\ 1) Department of Metallurgy and Ceramics Science, Tokyo Institute of Technology, 2-12-1 Ookayama, Meguro-ku, Tokyo, 152- \\ 8552 Japan. \\ 2) Department of Materials Science and Engineering, Tokyo Institute of Technology, 2-12-1 Ookayama, \\ Meguro-ku, Tokyo, 152-8552 Japan. \\ 3) R \& D Laboratories, Nippon Steel \& Sumitomo Metal Corporation, 20-1 Shintomi, Futtsu, Chiba, $293-8511$ Japan.
}

(Received on September 14, 2017; accepted on January 4, 2018)

\begin{abstract}
Reducibilities of silico-ferrite of calcium and aluminum (SFCA) have been examined using high temperature X-ray diffraction (XRD) analysis including the effect of hydrogen. Two types of sample were prepared: columnar SFCA covered with slag and acicular SFCA with fine pores, denoted by 'Columnar SFCA' and 'Acicular SFCA', respectively. These samples were synthesized using chemical reagents and iron ore powders. XRD analysis was applied to the samples heated in a condition simulating a blast furnace. Oxygen partial pressure was controlled by gas mixtures of $\mathrm{CO}-\mathrm{CO}_{2}-\mathrm{He}$, and there were some cases where 3.9 vol\% of hydrogen gas was added to the mixture. The microstructures of the samples before and after heating were observed by electron probe microanalysis (EPMA). XRD profiles indicated: (i) both SFCA samples were reduced to Fe via calcio-wüstite (CW), (ii) the reduction from 'Acicular SFCA' to CW took place at lower temperatures than that of 'Columnar SFCA' during the heating cycle up to $1000^{\circ} \mathrm{C}$, and (iii) $\mathrm{CW}$ produced from 'Acicular SFCA' was reduced to Fe earlier than CW from 'Columnar SFCA' at $1000^{\circ} \mathrm{C}$. These results suggest that SFCA and CW phases in 'Acicular SFCA' have higher reducibility than those in 'Columnar SFCA'. This would be because 'Acicular SFCA' consists of smaller SFCA particles with fine pores. BSE images have revealed that such microstructures still remained even after the reduction to $\mathrm{CW}$. Additions of hydrogen promoted reduction of 'Columnar SFCA' more effectively, and this effect was observed more remarkably in the reduction from CW to Fe than from SFCA to CW.
\end{abstract}

KEY WORDS: acicular SFCA; columnar SFCA; calcio-wüstite; high temperature X-ray diffraction; reduction; microstructure; hydrogen addition.

\section{Introduction}

Sinters are the main iron source for a blast furnace, and the reducibility of sinters is one of the crucial factors affecting the operation stability of a blast furnace. ${ }^{1-3)}$ Sinters are primarily composed of hematite $\left(\mathrm{Fe}_{2} \mathrm{O}_{3}\right)$, magnetite $\left(\mathrm{Fe}_{3} \mathrm{O}_{4}\right.$ ), calcium ferrite (mainly silico-ferrite of calcium and aluminum (SFCA)) and slag phases; among them, $\mathrm{Fe}_{2} \mathrm{O}_{3}$ and SFCA are in main proportion. Sinters are reduced in a blast furnace, which reduction process is very complicated because temperature as well as gas components change depending on the position of the furnace. This reduction normally proceeds via two steps: (i) $\mathrm{Fe}_{2} \mathrm{O}_{3}, \mathrm{Fe}_{3} \mathrm{O}_{4}$ and SFCA are reduced to wüstite in the lower temperature zone and (ii) wüstite is reduced to metallic iron $(\mathrm{Fe})$ in the thermal reserve zone and in the even higher temperature zone. The overall reduction efficiency of a blast furnace is dominated by the second-step reaction rate at higher temperatures. ${ }^{4-6}$ )

* Corresponding author: E-mail: cai.b.aa@m.titech.ac.jp DOI: http://dx.doi.org/10.2355/isijinternational.ISIJINT-2017-552
It is noted that there are two types of wüstite in reduced sinters: one is wüstite (denoted by $\mathrm{FeO}$ ) reduced from $\mathrm{Fe}_{2} \mathrm{O}_{3}$ containing less impurities and the other is calcio-wüstite (denoted by $\mathrm{CW}$ ) reduced from SFCA - both $\mathrm{FeO}$ and $\mathrm{CW}$ have the rock-salt structure. In the previous work, ${ }^{7)}$ it has been found from high temperature X-ray diffraction (XRD) analysis that the reducibility of $\mathrm{FeO}$ is higher than that of CW. Now it should also be noted that there are two types of SFCA that produces CW: one is columnar SFCA covered with slag and the other is acicular SFCA with fine pores. ${ }^{1)}$ Both types of SFCA are often contained in commercial sinters, and thus it is of great importance to evaluate the difference between the reducibilities of these two types of SFCA to optimize the production process of sinters.

Many studies have been made on the reducibilities of columnar and acicular SFCA, and several researchers have insisted from reduction experiments of practical sinters that the reduction rate of acicular SFCA is greater than that of columnar SFCA. ${ }^{1,3,8-11)}$ For example, Sato et al. ${ }^{1)}$ have evaluated the reducibilities of sinters from the viewpoint of the microstructures. They have found that the sinters mostly 
composed of acicular SFCA with fine pores have higher reduction index (RI) at $900^{\circ} \mathrm{C}$ than those composed of columnar SFCA covered with slag. Maeda and Ono ${ }^{3)}$ have also focused on the relation between the microstructure and the reducibility of sinters. They have observed the microstructures of two sinters having different phase constituents before and after heating in reducing gas, and have reported that acicular SFCA is reduced much faster than $\mathrm{Fe}_{2} \mathrm{O}_{3}$ and $\mathrm{Fe}_{3} \mathrm{O}_{4}$. These previous reports suggest that the reducibility of iron ores is dominated by constituent phases such as $\mathrm{Fe}_{2} \mathrm{O}_{3}, \mathrm{Fe}_{3} \mathrm{O}_{4}$, SFCA and slags as well as morphologies such as columnar and acicular SFCA. However, it is very difficult to conclude effects of the phases and morphologies on the reducibilities of columnar and acicular SFCA because systematic variation cannot be made for the fraction of constituent phase and its morphology as long as practical iron ores are used as samples.

On the other hand, Sakamoto et al. ${ }^{8)}$ have synthesized samples with a single sinter structure from chemical reagents. They have concluded that the sample composed of fine $\mathrm{Fe}_{2} \mathrm{O}_{3}$ and fine SFCA particles has higher reducibility than the sample with columnar SFCA covered with slag, which has been explained by faster diffusion of reducing gas through the sample having smaller particle sizes and less slag volume. As is the case with many other studies, Sakamoto et al. have carried out the reduction experiments at $900^{\circ} \mathrm{C}$, which is the same as that used for RI measurement. However, the reduction reaction from $\mathrm{FeO}$ or $\mathrm{CW}$ to Fe mostly proceeds at higher temperatures than $900^{\circ} \mathrm{C}$ in a blast furnace. Accordingly, to totally understand the reducibility of SFCA, reduction experiments should be made using samples with homogeneous microstructures at changing temperatures and oxygen partial pressures simulating a blast furnace condition, including the reduction process from $\mathrm{CW}$ to $\mathrm{Fe}$. Against this background, this study aims to compare the reducibilities between two types of SFCA, i.e., columnar SFCA covered with slag and acicular SFCA with fine pores, using high temperature $\mathrm{X}$-ray diffraction (XRD) analysis to discuss from the perspective of microstructure. In addition, hydrogen effect on the reducibility is also examined.

\section{Experimental}

\subsection{Preparation of SFCA Samples}

Samples used in this study were two types of synthesized samples having homogeneous structures: columnar SFCA covered with slag ('Columnar SFCA') and acicular SFCA with fine pores ('Acicular SFCA'). Table 1 shows the nominal compositions of these samples. 'Columnar SFCA' samples were synthesized according to the method conducted by Maeda and Ono. ${ }^{12)}$ Reagent grade powders of $\mathrm{Fe}_{2} \mathrm{O}_{3}, \mathrm{CaCO}_{3}, \mathrm{SiO}_{2}$ and $\mathrm{Al}_{2} \mathrm{O}_{3}$ were weighed to the desired compositions and mixed in an alumina mortar. The mixed

Table 1. Nominal compositions of columnar and acicular SFCA samples (mass\%).

\begin{tabular}{cccccc}
\hline & $\mathrm{Fe}_{2} \mathrm{O}_{3}$ & $\mathrm{SiO}_{2}$ & $\mathrm{CaO}$ & $\mathrm{Al}_{2} \mathrm{O}_{3}$ & $\mathrm{CaO} / \mathrm{SiO}_{2}$ \\
\hline Columnar & 65.0 & 7.8 & 23.3 & 3.9 & 3.0 \\
Acicular & 80.5 & 6.2 & 12.3 & 1.0 & 2.0 \\
\hline
\end{tabular}

powder was calcined at $1000^{\circ} \mathrm{C}$ for $3 \mathrm{~h}$, and then crushed and mixed again. The calcining, crushing and mixing processes were repeated three times. About $12 \mathrm{~g}$ of the powder was then charged into an alumina crucible and melted in air at $1300^{\circ} \mathrm{C}$ for $0.5 \mathrm{~h}$. Subsequently, the sample was cooled down to $1100^{\circ} \mathrm{C}$ at a cooling rate of $4.9^{\circ} \mathrm{C} / \mathrm{s}$, and then quenched into an ice-water mixture.

'Acicular SFCA' samples were synthesized using an iron ore and reagent grade $\mathrm{CaCO}_{3}$. The iron ore was crushed and sieved to obtain particles sized under $90 \mu \mathrm{m}$. The $\mathrm{CaCO}_{3}$ reagent was calcined in air for $24 \mathrm{~h}$ to obtain $\mathrm{CaO}$. Powdery iron ore and $\mathrm{CaO}$ were weighed so that the $\mathrm{CaO} / \mathrm{SiO}_{2}$ ratio was 2 , and then mixed in an alumina mortar. About $0.45 \mathrm{~g}$ of mixed powders were uniaxially pressed into a shape of disc using a piston cylinder die of $10 \mathrm{~mm}$ in diameter. The compaction pressure of $40 \mathrm{MPa}$ was applied for $30 \mathrm{~s}$. The prepared sample was heated in air at $1275^{\circ} \mathrm{C}$ for $10 \mathrm{~min}$, and then cooled down to room temperature in air.

Both 'Columnar SFCA' and 'Acicular SFCA' samples were crushed and sieved to obtain particles in the range 38-75 $\mu \mathrm{m}$ in diameter to be subjected to reduction experiments in a high temperature XRD apparatus.

\subsection{Characterization of Synthesized Samples}

Electron probe microanalysis (EPMA) was used to observe microstructures of synthesized SFCA samples, and the compositions of the phases were quantitatively analyzed by point analysis, where the beam diameter was about $1 \mu \mathrm{m}$. An accelerating voltage of $15 \mathrm{kV}$ and a probe current of 20 nA were used. For quantitative analysis, standard samples were prepared: $\mathrm{Fe}_{2} \mathrm{O}_{3}$ was used for $\mathrm{Fe}$, and a homogeneous glassy sample of 12.5 (mass $\%) \mathrm{Fe}_{2} \mathrm{O}_{3}-41.7 \mathrm{CaO}-33.3 \mathrm{SiO}_{2-}$ $12.5 \mathrm{Al}_{2} \mathrm{O}_{3}$ for $\mathrm{Si}, \mathrm{Ca}, \mathrm{Al}$ and $\mathrm{O}$.

Some of columnar and acicular SFCA samples were crushed into fine powders using an alumina mortar and a pestle and were subjected to XRD analysis to identify major constituent phases before heating. This XRD analysis was carried out with $\mathrm{CoK} \alpha$ radiation at an accelerating voltage of $40 \mathrm{kV}$ and a filament current of $250 \mathrm{~mA}$. The optical system of a parallel beam was employed. The diffractionscanning rate was $0.5^{\circ} / \mathrm{min}$, and the scan range of $2 \theta$ was between $10^{\circ}$ and $80^{\circ}$ covering all the compounds in the samples.

\subsection{Reduction Experiments in High Temperature XRD Apparatus}

About $400 \mathrm{mg}$ of sample powders were mounted into a shallow flat alumina holder $(17 \mathrm{~mm}$ length $\times 9 \mathrm{~mm}$ width $\times$ $0.8 \mathrm{~mm}$ depth). The holder was horizontally placed on the heating plate with a Pt heating element in the center of the furnace. To protect the sample powders from reacting with the holder, an iron foil $0.1 \mathrm{~mm}$ thick was placed under the sample powders. The iron foil is not considered to affect the experimental system because it has been confirmed after the experiment that the iron foil is not reacted with the sample powders. The furnace was installed in the sample chamber ( $\Phi 116 \mathrm{~mm} \times 102 \mathrm{~mm}$ depth) of a high temperature X-ray diffractometer as shown in Fig. 1. ${ }^{7)}$ The X-ray generator had the maximum power of $10 \mathrm{~kW}(40 \mathrm{kV}$ and $250 \mathrm{~mA})$. The Co-K $\alpha$ line was used as the X-ray source. The optical system of a parallel beam was employed. The scan range of 


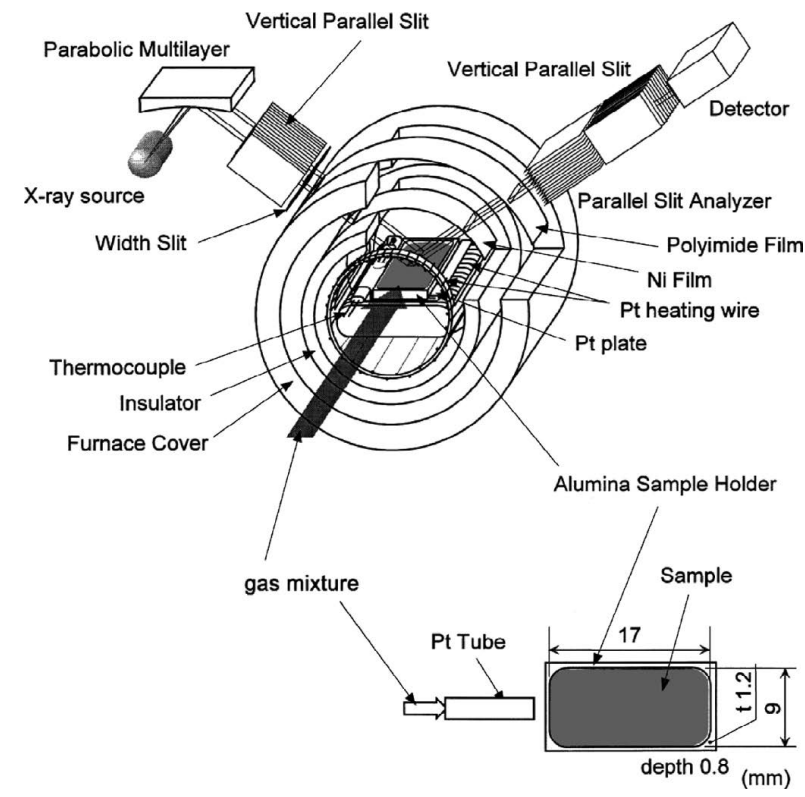

Fig. 1. Schematic diagram of the high-temperature X-ray diffractometer.

$2 \theta$ was $33-55^{\circ}$ covering the peaks of the main compounds. The diffraction scan rate was $5 \% \mathrm{~min}$ and the scan step was $0.02^{\circ}$. To know the relative amounts of SFCA and CW, diffraction peak areas were derived from XRD profiles. To evaluate the change with time in the peak area more accurately, a diffraction scan rate of $1 \%$ min and a scan step of $0.02^{\circ}$ were employed in the $2 \theta$ range of $39.3-41.6^{\circ}$ and $47.2-49.5^{\circ}$, respectively, for SFCA and CW. The diffraction angle was calibrated by means of the external standard specimen method using high purity silicon powders at room temperature. Temperature of samples was measured by an R-type thermocouple placed in the vicinity of the sample with the accuracy of $\pm 0.1^{\circ} \mathrm{C}$.

Figure 2 shows the experimental conditions of temperature and gas composition in the present study, which are the same as in the previous work. ${ }^{7)}$ Oxygen partial pressure in the furnace was adjusted using gas mixtures of $\mathrm{CO}-\mathrm{CO}_{2}$, the ratio of which was changed depending on temperature to simulate a blast furnace condition. To improve X-ray diffraction intensity, the gas mixture was further diluted with $50 \mathrm{vol} \%$ of helium gas although there is no helium gas added in the actual blast furnace condition. The ratio of $\mathrm{CO} /$ $\mathrm{CO}_{2}$ is set to be the same as not added so as for the oxygen partial pressure to be the same as that in the blast furnace condition. The gas mixture was introduced to the surface of the sample through a Pt tube $(3.5 \mathrm{~mm}$ inner diameter) placed at the center of the front door of the furnace. The total flow rate of the gas mixture was $1.67 \times 10^{-6} \mathrm{~m}^{3} / \mathrm{s}(100$ $\mathrm{ml} / \mathrm{min}$ ). The gas mixture was discharged through the hole at the bottom of the furnace to the outside of the system. To simulate the condition of the thermal reserve zone, the sample was heated from room temperature to $1000^{\circ} \mathrm{C}$ with a heating rate of $5^{\circ} \mathrm{C} / \mathrm{min}$ (Step I), held at $1000^{\circ} \mathrm{C}$ for 100 $\min$ (Step II) and then heated again up to $1250^{\circ} \mathrm{C}$ at a heating rate of $5^{\circ} \mathrm{C} / \mathrm{min}$ (Step III). During Steps I and III, temperature continuously increased at a heating rate of $5^{\circ} \mathrm{C} /$ min, resulting in a temperature increment of $24^{\circ} \mathrm{C}$ per scan covering the $2 \theta$ range of $33-55^{\circ}$. Preliminary experiment examines whether the current flow rate is gas supply rate

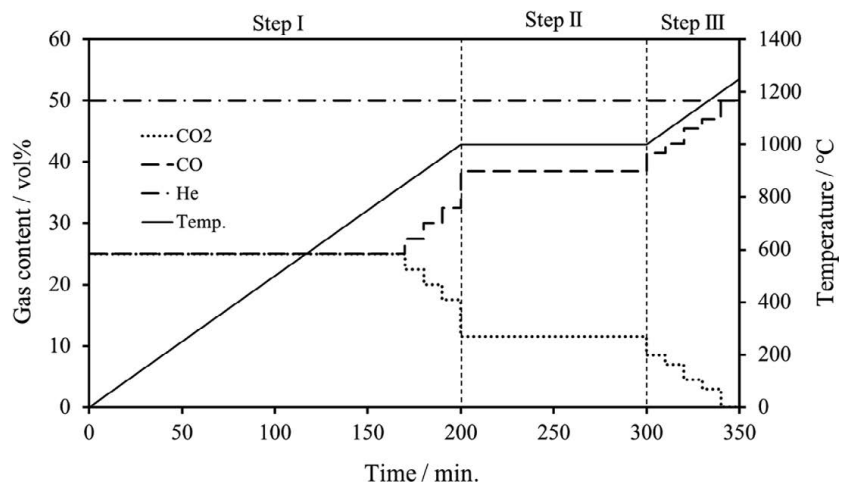

Fig. 2. Experimental conditions of temperature and gas composition.

controlling: Two sintered ore powder samples were used for reduction under the same heating history above-mentioned with the total flow rate of $1.67 \times 10^{-6} \mathrm{~m}^{3} / \mathrm{s}(100 \mathrm{ml} / \mathrm{min})$ and $3.34 \times 10^{-6} \mathrm{~m}^{3} / \mathrm{s}(200 \mathrm{~min} / \mathrm{ml})$ respectively. The same results were obtained in both samples. Consequently, the current flow rate of $1.67 \times 10^{-6} \mathrm{~m}^{3} / \mathrm{s}$ is not supply rate controlling. These reduction experiments were repeated four times for 'Columnar SFCA' and twice for 'Acicular SFCA'. For reduction experiments with hydrogen, 3.9 vol\% of $\mathrm{H}_{2}$ was also added to the gas mixture. As a result, the total flow of gas mixture was $1.73 \times 10^{-6} \mathrm{~m}^{3} / \mathrm{s}(103.9 \mathrm{ml} / \mathrm{min})$. According to the FactSage thermodynamical software and databases, the calculated oxygen partial pressures with and without hydrogen addition are almost identical: For example, the oxygen partial pressures at $1000^{\circ} \mathrm{C}$ are $6.6 \times 10^{-16} \mathrm{~atm}$ and $5.0 \times 10^{-16}$ atm for with and without hydrogen addition, respectively.

\subsection{Confirmation of Microstructure Change in SFCA Samples}

Two 'Acicular SFCA' samples and two 'Columnar SFCA' samples were employed. About $38 \mathrm{mg}$ of sample powders were mounted into an alumina crucible $(4 \mathrm{~mm}$ diameter $\times 3 \mathrm{~mm}$ height), and the crucible was horizontally placed in the center of an infrared image furnace. The samples were heated up to $1000^{\circ} \mathrm{C}$ in the same reducing atmosphere as in Fig. 2; in $220 \mathrm{~min}$ and $235 \mathrm{~min}$ for 'Acicular SFCA' samples and in $240 \mathrm{~min}$ and $280 \mathrm{~min}$ for 'Columnar SFCA' samples, these samples were cooled down to room temperature, where temperature decreased down to $500^{\circ} \mathrm{C}$ in $25 \mathrm{~s}$ and to $150^{\circ} \mathrm{C}$ in another $70 \mathrm{~s}$. Temperature of the furnace was controlled using a B-type thermocouple placed at the sample holder. Temperature of the sample surface was calibrated using the melting point of $\mathrm{Au}$, which was placed at the same position as SFCA samples; resultantly, the temperature uniformity of the sample was within $\pm 5^{\circ} \mathrm{C}$. Finally, these samples were subjected to EPMA observation.

\section{Results}

\subsection{Microstructures and Phases of Synthesized Sam- ples}

Figure 3 shows two typical back-scattered electron (BSE) images of a 'Columnar SFCA' sample, where Fig. 3(a) contains skeleton hematite and slag observed near the alumina crucible, and Fig. 3(b) contains columnar SFCA phases 

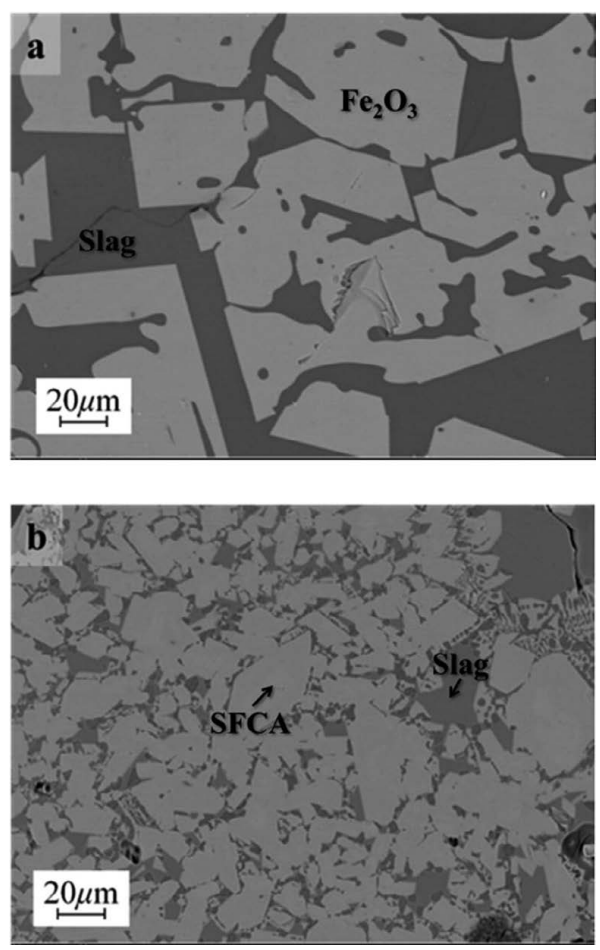

Fig. 3. Two typical back-scattered electron (BSE) images of a 'Columnar SFCA' sample. a: Near the alumina crucible b: Inside the sample far from the crucible.
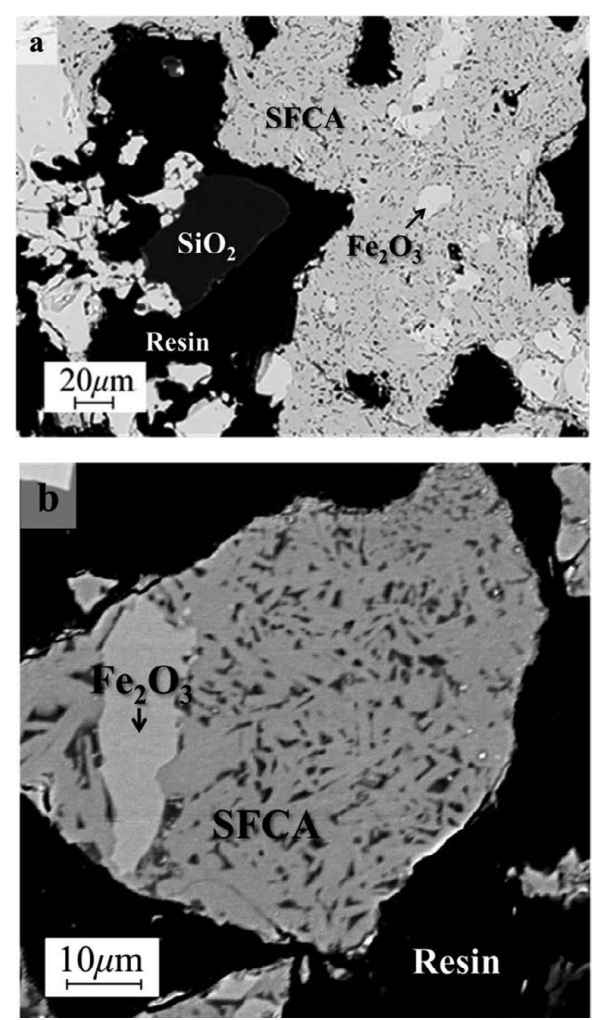

Fig. 4. A typical BSE image of an 'Acicular SFCA' sample. a: Bulk b: Powder after sieving.

(typically $60 \mu \mathrm{m}$ in major axis $\times 10 \mu \mathrm{m}$ in minor axis), which are closely covered with slag phase and observed inside the sample far from the crucible. This difference in microstructures may stem from the sample composition change due to alumina pick-up from the crucible, which would lead to the formation of skeleton hematite. Meanwhile, XRD cannot distinguish between $\mathrm{Fe}_{2} \mathrm{O}_{3}$-origin $\mathrm{FeO}$
Table 2. Chemical compositions of the SFCA and slag phases in the 'Columnar SFCA' sample and of the SFCA phase in the 'Acicular SFCA' sample (mass\%). The numbers in parentheses are the standard deviations of 5 point analyses for each phase.

\begin{tabular}{ccccccc}
\hline Phase & $\mathrm{Fe}_{2} \mathrm{O}_{3}$ & $\mathrm{CaO}$ & $\mathrm{SiO}_{2}$ & $\mathrm{Al}_{2} \mathrm{O}_{3}$ & $\mathrm{CaO} / \mathrm{SiO}_{2}$ & $\mathrm{Al}_{2} \mathrm{O}_{3} / \mathrm{SiO}_{2}$ \\
\hline $\begin{array}{c}\text { SFCA in } \\
\text { 'Columnar }\end{array}$ & 79.22 & 12.17 & 3.62 & 4.99 & 3.36 & 1.38 \\
$\begin{array}{c}\text { SFCA' } \\
(1.47)\end{array}$ & $(0.31)$ & $(0.16)$ & $(0.11)$ & $(0.07)$ & $(0.07)$ \\
$\begin{array}{l}\text { Slag in } \\
\text { 'Columnar }\end{array}$ & 1.25 & 56.76 & 36.61 & 5.38 & 1.55 & 0.15 \\
$\begin{array}{c}\text { SFCA' } \\
(0.13)\end{array}$ & $(1.24)$ & $(0.47)$ & $(0.14)$ & $(0.03)$ & $(0.04)$ \\
$\begin{array}{l}\text { SFCA in } \\
\text { 'Acicular }\end{array}$ & 82.48 & 11.55 & 4.86 & 1.11 & 2.38 & 0.23 \\
SFCA' & $(2.10)$ & $(0.28)$ & $(0.15)$ & $(0.09)$ & $(0.06)$ & $(0.11)$ \\
\hline
\end{tabular}
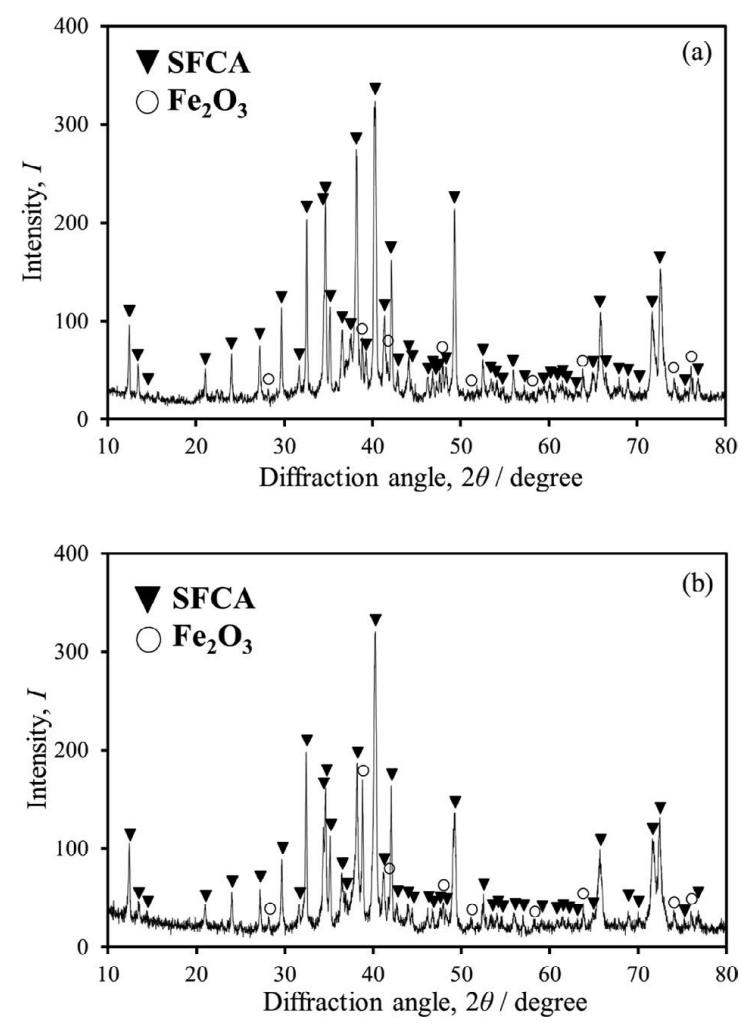

Fig. 5. XRD profiles measured at room temperature (a) for 'Columnar SFCA' and (b) for 'Acicular SFCA'.

peaks and SFCA-origin CW peaks. To avoid such a situation, the outer part of the sample was removed as much as possible before reduction experiment.

Figure 4(a) shows a typical BSE image of an 'Acicular SFCA' sample. There are three different phases observed: acicular SFCA, granular $\mathrm{Fe}_{2} \mathrm{O}_{3}$ and $\mathrm{SiO}_{2}$. However, $\mathrm{Fe}_{2} \mathrm{O}_{3}$ phase is a minor part of SFCA and this sample is reasonable for examining the reducibility of SFCA. Figure 4(b) shows a BSE image for 'Acicular SFCA' powder after sieving. It can be seen more clearly that SFCA is in an acicular (or plate-like) shape (typically $10 \mu \mathrm{m}$ in major axis $\times 0.5 \mu \mathrm{m}$ in minor axis) and that 'Acicular SFCA' have many fine pores around SFCA phase.

Table 2 summarizes the chemical compositions of the SFCA and slag phases in the 'Columnar SFCA' sample and of the SFCA phase in the 'Acicular SFCA' sample. The compositions are the averages for five positions in crosssectional areas. The numbers in parentheses are the standard deviations of 5 point analyses for each phase. Table 2 indi- 
cates that the SFCA phases in both samples are quaternary calcium ferrite, the compositions of which are close to each other. Figures 5(a) and 5(b) show XRD profiles measured at room temperature (a) for 'Columnar SFCA' and (b) for 'Acicular SFCA'. It can be seen that both samples have the XRD peaks at the angles where the diffraction peaks due to SFCA should be observed. It is generally known that acicular calcium ferrite has a different crystalline structure from columnar calcium called SFCA-I. ${ }^{13-17)}$ It has been reported that the content of $\mathrm{SiO}_{2}$ in SFCA-I is around 1 mass\%. ${ }^{17)}$ However, the SFCA obtained in this study contains ca. 3.62 mass $\% \mathrm{SiO}_{2}$. Therefore, the acicular SFCA observed in this study is considered to be different from the SFCA-I reported by the previous studies. The intensities of $\mathrm{Fe}_{2} \mathrm{O}_{3}$ peaks in Fig. 5(a) are smaller than in Fig. 5(b), suggesting that the volume fraction of $\mathrm{Fe}_{2} \mathrm{O}_{3}$ phase in 'Columnar SFCA' is smaller than in 'Acicular SFCA'. Accordingly, the 'Columnar SFCA' sample can also be used for the purpose of the present work. Thus, the SFCA phases in both samples are very close to each other in terms of chemical composition and crystal structure but different in terms of the morphology of SFCA and the presence of fine pores around it.

\subsection{Reduction Process in Terms of High Temperature XRD Analysis}

Figures 6 and 7 show typical XRD profiles of the columnar and acicular SFCA samples reduced in atmosphere with no hydrogen addition, respectively, for Step I (Figs. 6(a) and 7(a)), Step II (Figs. 6(b) and 7(b)) and Step III (Figs. 6(c) and $7(\mathrm{c})$ ), where temperature on the right or the left side of Figs. 6(a), 6(c), 7(a) and 7(c) represents one at which each scan was started for Steps I and III, and time on the left side of Figs. 6(b) and 7(b) represents the total time after heating was started. Figures 8 and 9 show XRD profiles of the columnar and acicular SFCA samples reduced in atmosphere with hydrogen addition for Step I (Figs. 8(a) and 9(a)), Step II (Figs. 8(b) and 9(b)) and Step III (Figs. 8(c) and $9(\mathrm{c})$ ). On the basis of these four figures, Table 3 summarizes temperatures at which peaks due to $\mathrm{Fe}_{2} \mathrm{O}_{3}, \mathrm{Fe}_{3} \mathrm{O}_{4}$, SFCA, dicalcium-silicate $\left(2 \mathrm{CaO} \cdot \mathrm{SiO}_{2}\right.$ denoted as $\left.\mathrm{C}_{2} \mathrm{~S}\right), \mathrm{CW}$ and $\mathrm{Fe}$ appear or disappear in both 'Columnar SFCA' and 'Acicular SFCA', where the time in the bracket represents when $\mathrm{CW}$ disappear and $\mathrm{Fe}$ appear at $1000^{\circ} \mathrm{C}$, and $\left(+\mathrm{H}_{2}\right)$ represents the reduction with hydrogen additions. Repeated experiments have revealed that all these data are reproducible within $\pm 5^{\circ} \mathrm{C}$ for temperature in Step I and within \pm $1 \mathrm{~min}$ for time in Step II. It is found from Table 3 that in case of no hydrogen additions, SFCA and CW phases in 'Acicular SFCA' disappear at lower temperatures than those in 'Columnar SFCA'. In addition, it seems that hydrogen additions promote disappearance of SFCA and CW more effectively in 'Columnar SFCA'. These results are discussed in detail in the discussion section.

\subsection{Microstructure of Reduced Sample}

Figures 10(a) and 10(b) shows BSE images of 'Columnar SFCA' powders after reduction where the samples were quenched at (a) $240 \mathrm{~min}$ and (b) $280 \mathrm{~min}$ in Step II. The microstructure in Fig. 10(a) consists of three phases, i.e., $\mathrm{CW}$ reduced from columnar SFCA, Fe and slag phases. Small amount of columnar SFCA is reduced to $\mathrm{Fe}$ and residual columnar SFCA is reduced to $\mathrm{CW}$ at $240 \mathrm{~min}$. At
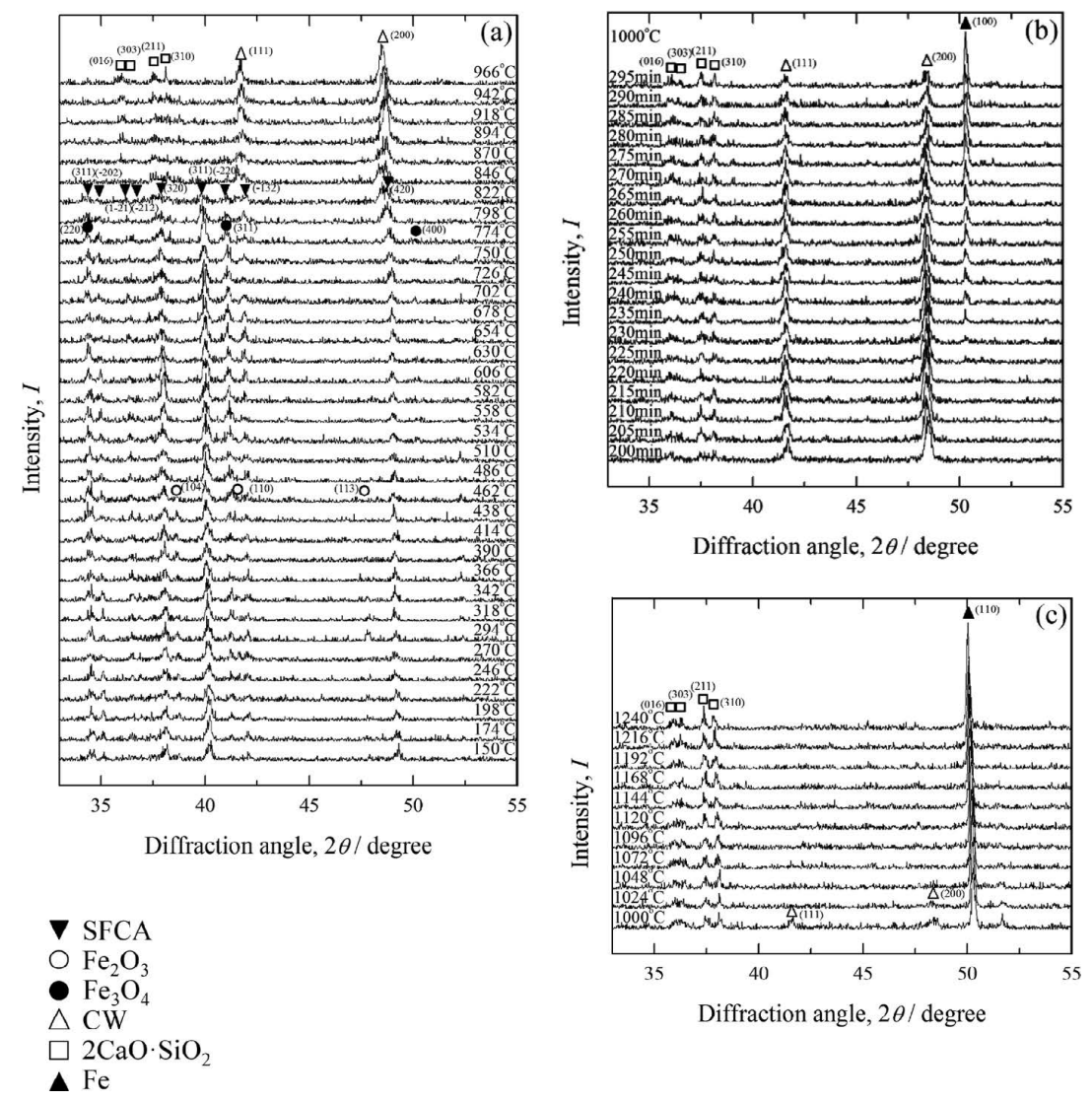

Fig. 6. Typical XRD profiles of the columnar SFCA sample reduced in atmosphere with no hydrogen addition for Step I (a), Step II (b) and Step III (c). 

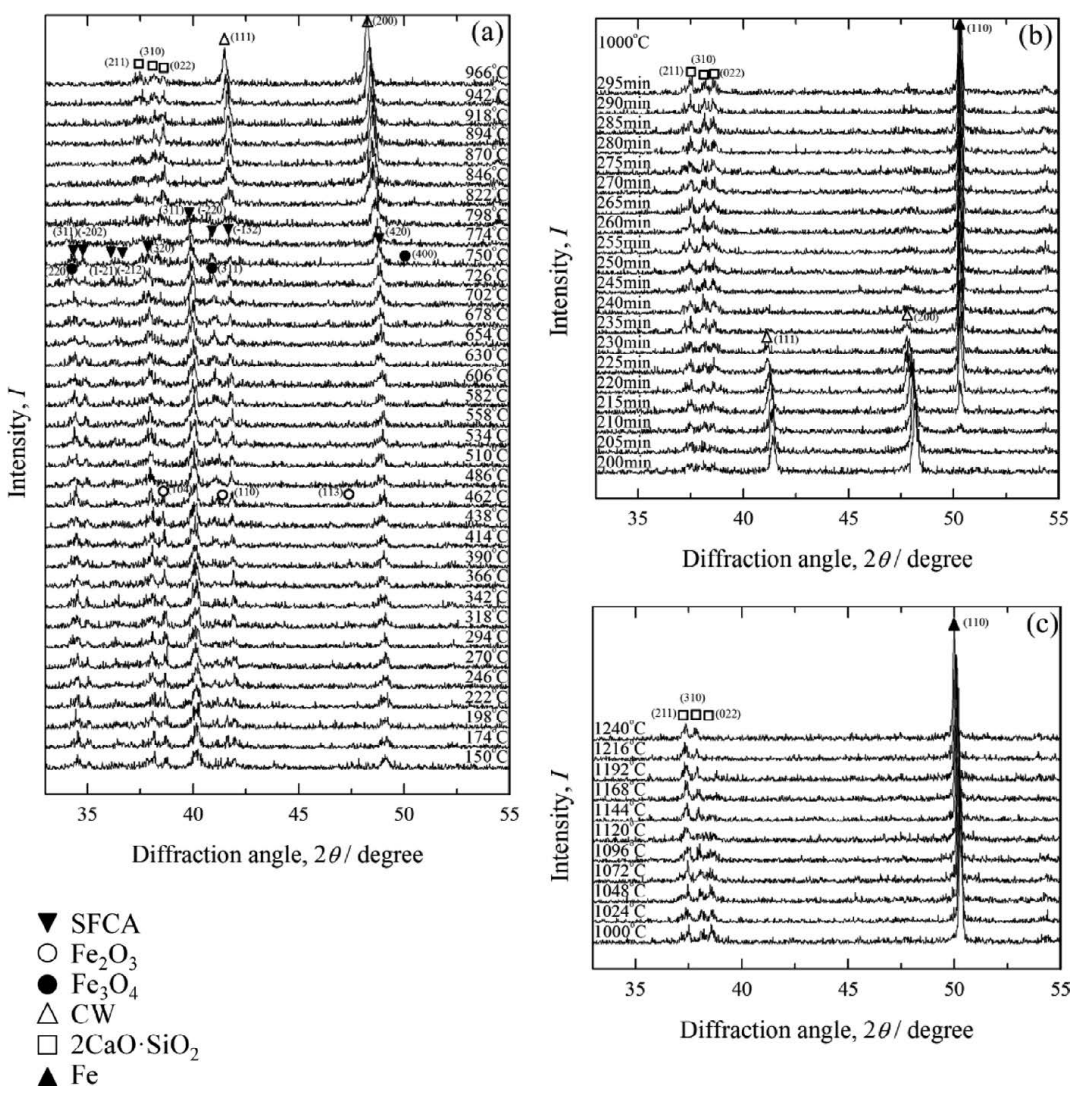

Fig. 7. Typical XRD profiles of the acicular SFCA sample reduced in atmosphere with no hydrogen addition for Step I (a), Step II (b) and Step III (c).
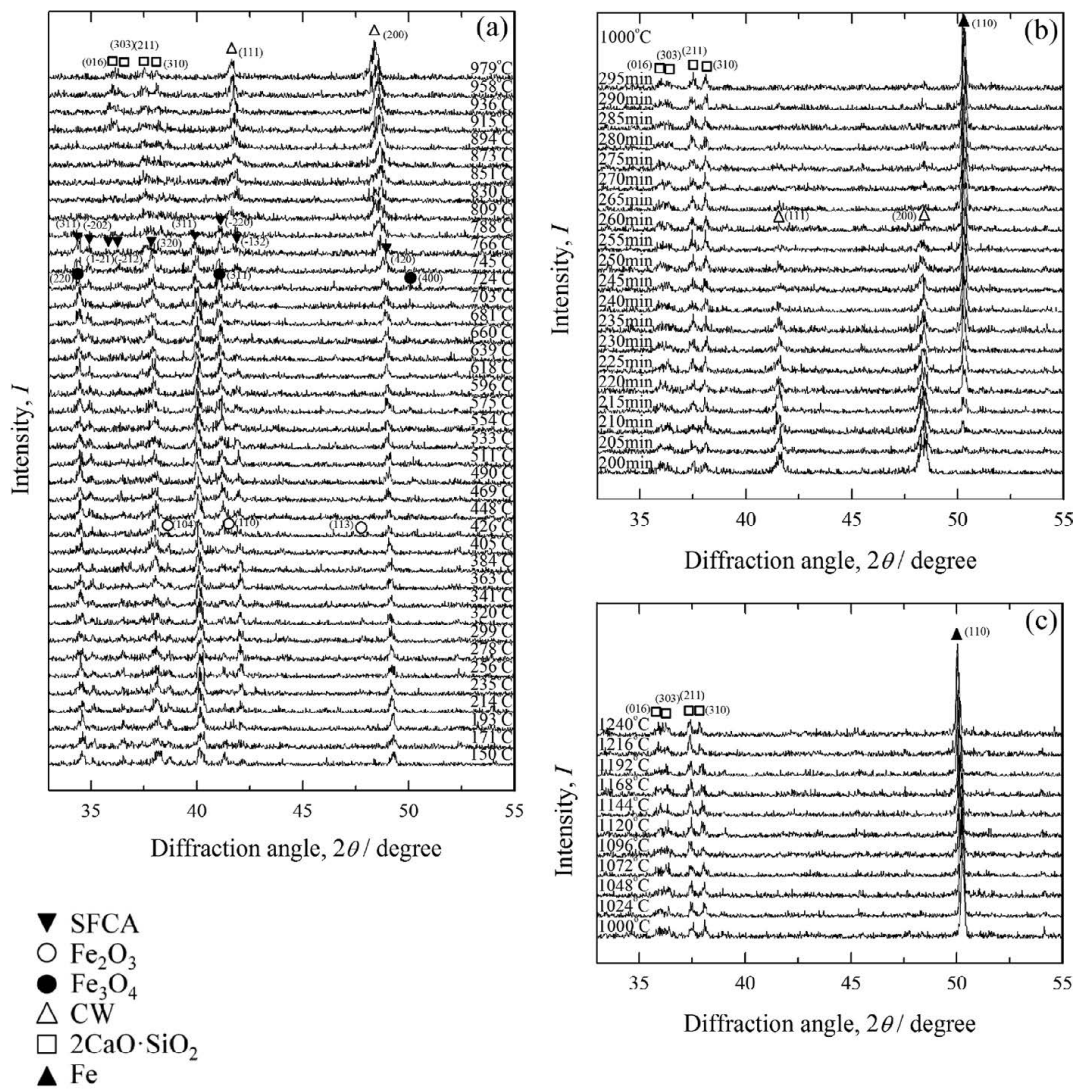

Fig. 8. XRD profiles of the columnar SFCA sample reduced in atmosphere with hydrogen addition for Step I (a), Step II (b) and Step III (c).

280 min in Step II, as shown in Fig. 10(b), the microstructure consists of $\mathrm{CW}, \mathrm{Fe}$, slag and silicates originating from gangue minerals originally contained in SFCA (hereinafter denoted as 'silicate'). Most parts of CW have been reduced to $\mathrm{Fe}$ at $280 \mathrm{~min}$.

Figures 11(a) and 11(b) shows BSE images of 'Acicular 


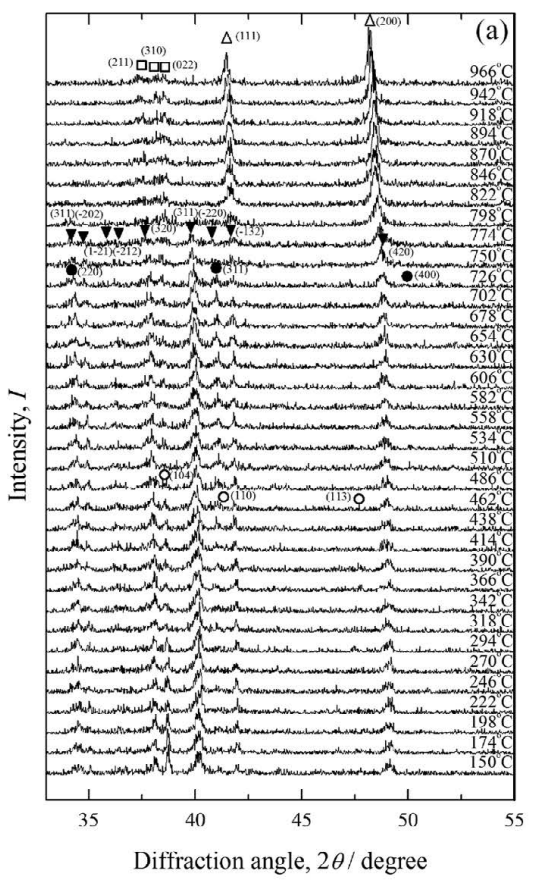

$\mathrm{SFCA}$
$\bigcirc \mathrm{Fe}_{2} \mathrm{O}_{3}$
$-\mathrm{Fe}_{3} \mathrm{O}_{4}$
$\triangle \mathrm{CW}$
$\square 2 \mathrm{CaO} \cdot \mathrm{SiO}_{2}$
$\triangle \mathrm{Fe}$
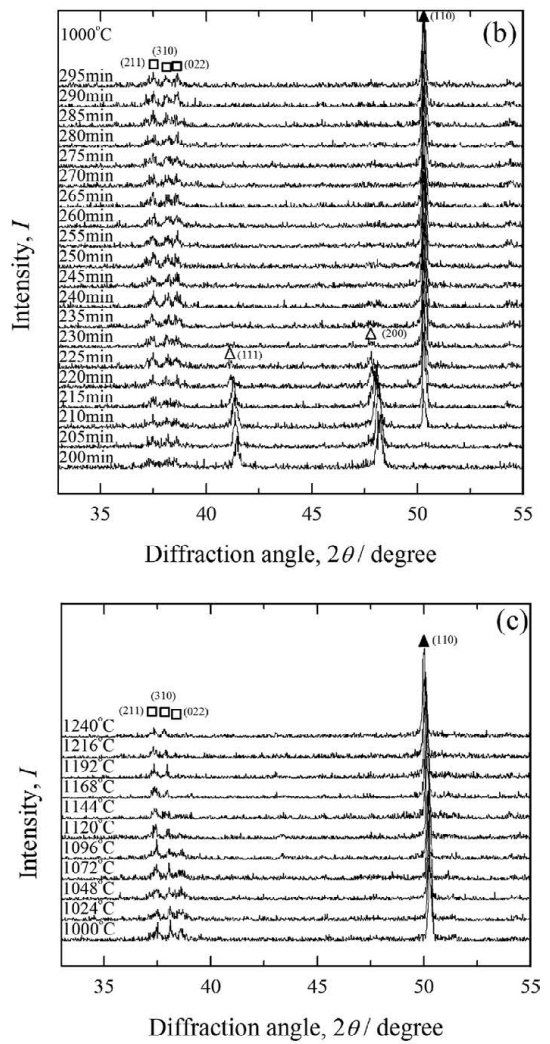

Fig. 9. XRD profiles of the acicular SFCA sample reduced in atmosphere with hydrogen addition for Step I (a), Step II (b) and Step III (c).

Table 3. Temperatures $\left({ }^{\circ} \mathrm{C}\right)$ at which peaks due to $\mathrm{Fe}_{2} \mathrm{O}_{3}, \mathrm{Fe}_{3} \mathrm{O}_{4}$, SFCA, $\mathrm{C}_{2} \mathrm{~S}, \mathrm{CW}$ and $\mathrm{Fe}$ appear or disappear in both 'Columnar SFCA' and 'Acicular SFCA', where the time in the bracket represents when $\mathrm{CW}$ disappear and $\mathrm{Fe}$ appear at $1000^{\circ} \mathrm{C}$, and $\left(+\mathrm{H}_{2}\right)$ represents the reduction with hydrogen additions.

\begin{tabular}{ccccc}
\hline & $\begin{array}{c}\text { Columnar } \\
\text { SFCA }\end{array}$ & $\begin{array}{c}\text { Columnar } \\
\text { SFCA }\left(+\mathrm{H}_{2}\right)\end{array}$ & $\begin{array}{c}\text { Acicular } \\
\text { SFCA }\end{array}$ & $\begin{array}{c}\text { Acicular } \\
\text { SFCA }\left(+\mathrm{H}_{2}\right)\end{array}$ \\
\hline $\begin{array}{c}\mathrm{Fe}_{2} \mathrm{O}_{3} \\
\text { disappear }\end{array}$ & 495 & 457 & 495 & 495 \\
$\begin{array}{c}\mathrm{Fe}_{3} \mathrm{O}_{4} \\
\text { appear }\end{array}$ & 471 & 435 & 495 & 495 \\
$\begin{array}{c}\mathrm{Fe}_{3} \mathrm{O}_{4} \\
\text { disappear }\end{array}$ & 807 & 753 & 759 & 759 \\
$\begin{array}{c}\mathrm{SFCA} \\
\text { disappear }\end{array}$ & 855 & 816 & 815 & 815 \\
$\begin{array}{c}\mathrm{C}_{2} \mathrm{~S} \\
\text { appear } \\
\mathrm{CW}\end{array}$ & 789 & 750 & 750 & 750 \\
appear & 789 & 750 & 750 & 748 \\
$\mathrm{CW}$ & 1046 & 1000 & 1000 & 1000 \\
disappear & $(264 \mathrm{~min})$ & $(239 \mathrm{~min})$ & $(234 \mathrm{~min})$ \\
$\mathrm{Fe}$ appear & 1000 & 1000 & 1000 & 1000 \\
& $(239 \mathrm{~min})$ & $(214 \mathrm{~min})$ & $(219 \mathrm{~min})$ & $(214 \mathrm{~min})$ \\
\hline
\end{tabular}

SFCA' powders after reduction where the samples were quenched at (a) $220 \mathrm{~min}$ and (b) $235 \mathrm{~min}$ in Step II. The microstructure before reduction shown in Fig. 4(b) contains only SFCA and $\mathrm{Fe}_{2} \mathrm{O}_{3}$ phases; in contrast, the microstructure in Fig. 11(a) consists of four phases, i.e., CW reduced from acicular SFCA, $\mathrm{FeO}$ reduced from $\mathrm{Fe}_{2} \mathrm{O}_{3}, \mathrm{Fe}$ and 'silicate' phases. Parts of acicular SFCA and $\mathrm{Fe}_{2} \mathrm{O}_{3}$ phases
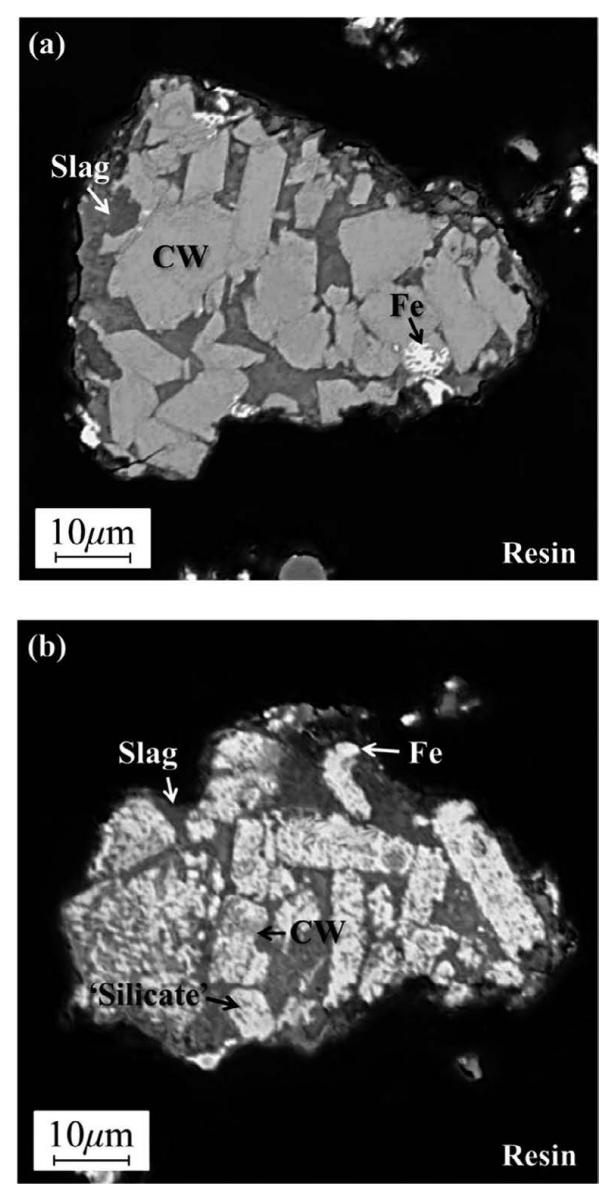

Fig. 10. BSE images of 'Columnar SFCA' powders after reduction where the samples were quenched at (a) $240 \mathrm{~min}$ and (b) $280 \mathrm{~min}$ in Step II. 

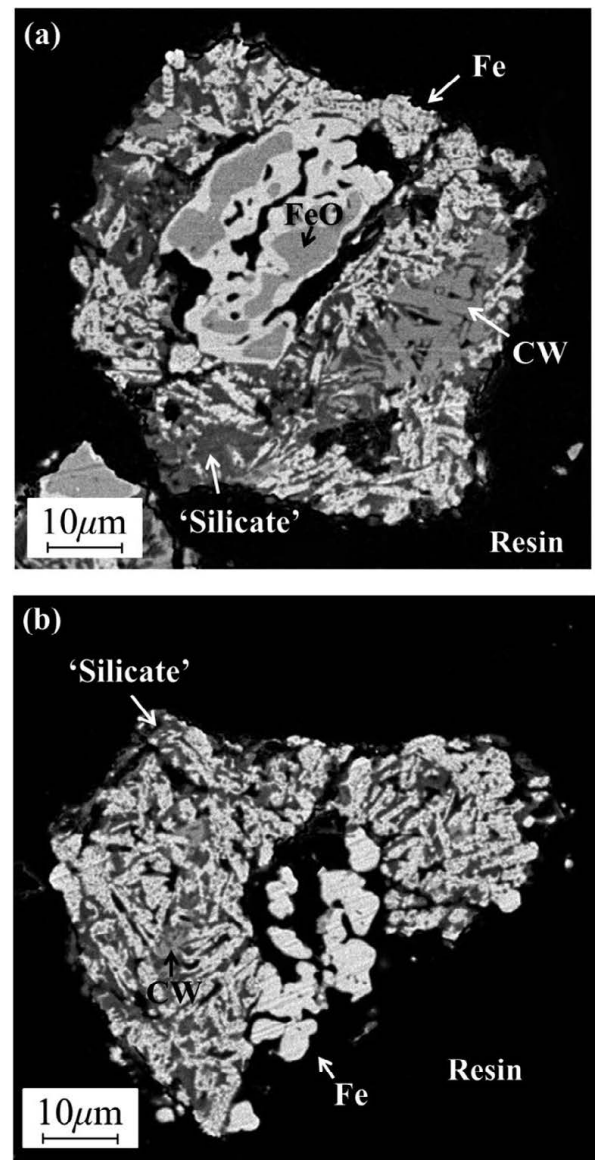

Fig. 11. BSE images of 'Acicular SFCA' powders after reduction where the samples were quenched at (a) $220 \mathrm{~min}$ and (b) $235 \mathrm{~min}$ in Step II.

are reduced to $\mathrm{Fe}$ at $220 \mathrm{~min}$. It should be noted that most parts of $\mathrm{CW}$ phase still keep the same structure as acicular SFCA and have fine pores nearby. At $235 \mathrm{~min}$ in Step II, as shown in Fig. 11(b), the microstructure consists of $\mathrm{CW}$, $\mathrm{Fe}$ and 'silicate' phases but most parts of $\mathrm{CW}$ and $\mathrm{FeO}$ are reduced to Fe. At this stage, 'silicate' formed by heating fills parts of fine pores; however, fine pores still remain around CW phase originating from SFCA phase.

\section{Discussion}

\subsection{Reduction from SFCA to CW}

To evaluate the reducibility of SFCA, XRD profiles shown in Figs. 6-9 are examined in more detail for SFCA, $\mathrm{Fe}_{2} \mathrm{O}_{3} \mathrm{Fe}_{3} \mathrm{O}_{4}$ and $\mathrm{CW}$ phases. For example, Figs. 12(a) and 12(b) are more accurate XRD profiles around (a) SFCA (311) peak and (b) $\mathrm{Fe}_{3} \mathrm{O}_{4}$ (400) peak for 'Columnar SFCA': the former was recorded at $702^{\circ} \mathrm{C}$ and the latter at $712^{\circ} \mathrm{C}$. The peak area corresponds to the relative amount of each phase present when measuring. To evaluate the relative amount of the phase, the XRD profiles relevant to SFCA (311), $\mathrm{Fe}_{2} \mathrm{O}_{3}$ (104), $\mathrm{Fe}_{3} \mathrm{O}_{4}$ (400) and $\mathrm{CW}$ (200) peaks are regressed to the Pseudo-Voigt function, ${ }^{7)}$ as shown in Fig. 12 , to derive the peak areas.

Figures 13 and 14 show the change with time in the relative amounts of $\mathrm{SFCA}, \mathrm{Fe}_{2} \mathrm{O}_{3}, \mathrm{Fe}_{3} \mathrm{O}_{4}$ and $\mathrm{CW}$ phases in 'Columnar SFCA' and 'Acicular SFCA', respectively, together with the temperature history. The relative amount means the value of the peak areas calculated by
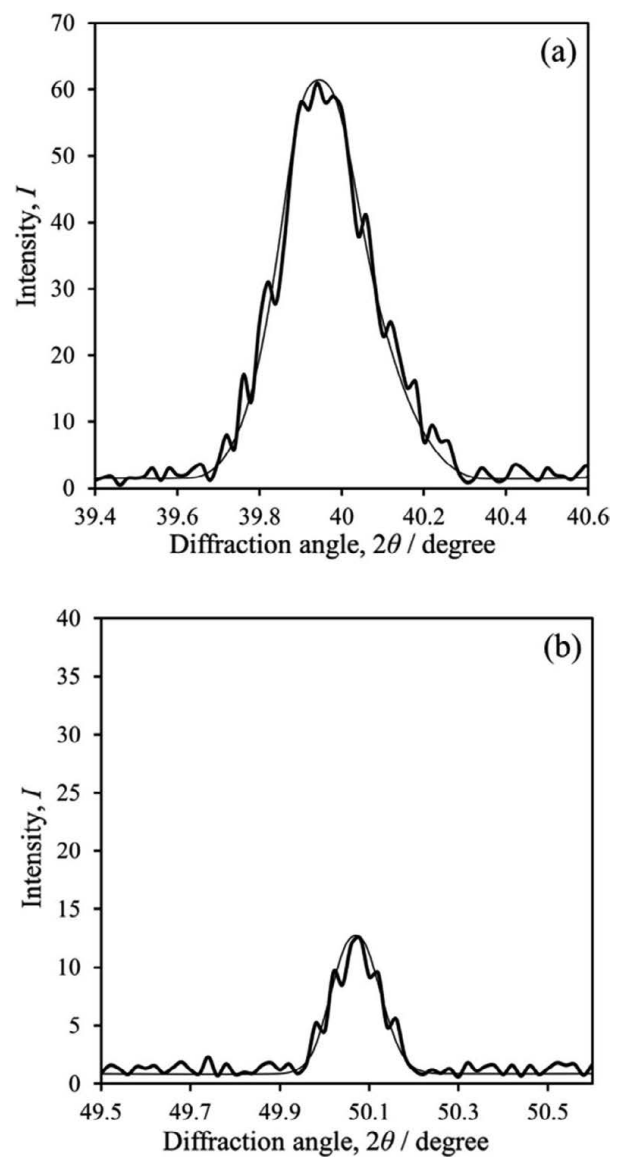

Fig. 12. Close-ups of XRD profiles around (a) SFCA (311) peak and (b) $\mathrm{Fe}_{3} \mathrm{O}_{4}$ (400) peak for 'Columnar SFCA': the former was recorded at $702^{\circ} \mathrm{C}$ and the latter at $712^{\circ} \mathrm{C}$. The profiles fitted to the Pseudo-Voigt function are also included.

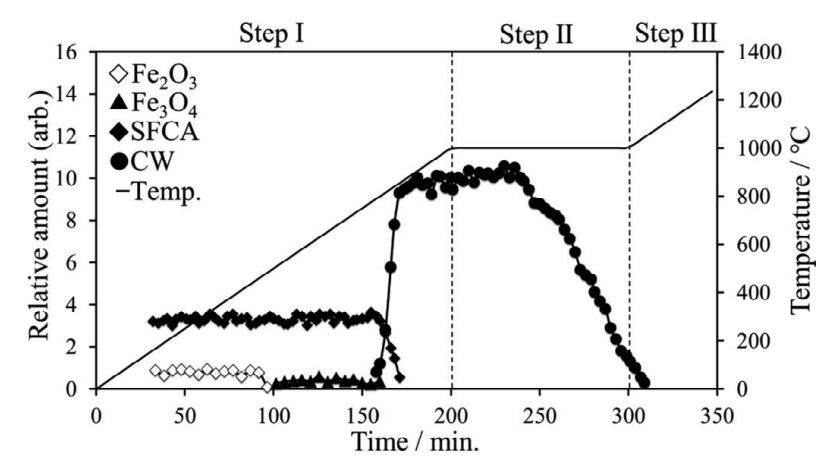

Fig. 13. Changes with time in the relative amounts of SFCA, $\mathrm{Fe}_{2} \mathrm{O}_{3}, \mathrm{Fe}_{3} \mathrm{O}_{4}$ and $\mathrm{CW}$ phases in 'Columnar SFCA' together with the temperature history.

Pseudo-Voigt function. In both figures, SFCA and $\mathrm{Fe}_{2} \mathrm{O}_{3}$ exist at room temperature; as temperature rises, SFCA starts to decrease; instead, $\mathrm{CW}$ starts to appear at $750^{\circ} \mathrm{C}$ for 'Acicular SFCA' and at $789^{\circ} \mathrm{C}$ for 'Columnar SFCA'. SFCA finally disappears at $815^{\circ} \mathrm{C}$ for 'Acicular SFCA' and at $855^{\circ} \mathrm{C}$ for 'Columnar SFCA'. These results indicate that SFCA is reduced to $\mathrm{CW}$ and the differences in temperature suggest that 'Acicular SFCA' has better reducibility than 'Columnar SFCA', which is consistent with the previous studies. ${ }^{1,3,8-11)}$ As mentioned in 3.1, the SFCA phases in both samples are very close to each other in terms of chemical composition and crystal structure but different in terms of the morphology of SFCA and the presence of fine pores 


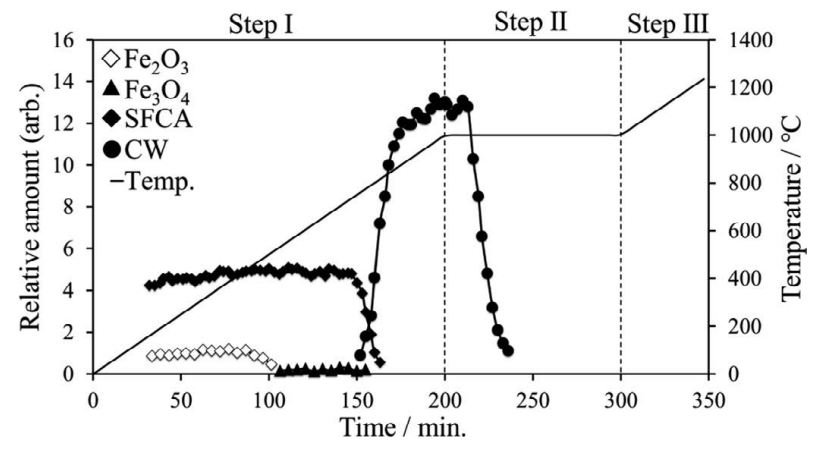

Fig. 14. Changes with time in the relative amounts of SFCA, $\mathrm{Fe}_{2} \mathrm{O}_{3}, \mathrm{Fe}_{3} \mathrm{O}_{4}$ and $\mathrm{CW}$ phases in 'Acicular SFCA' together with the temperature history.

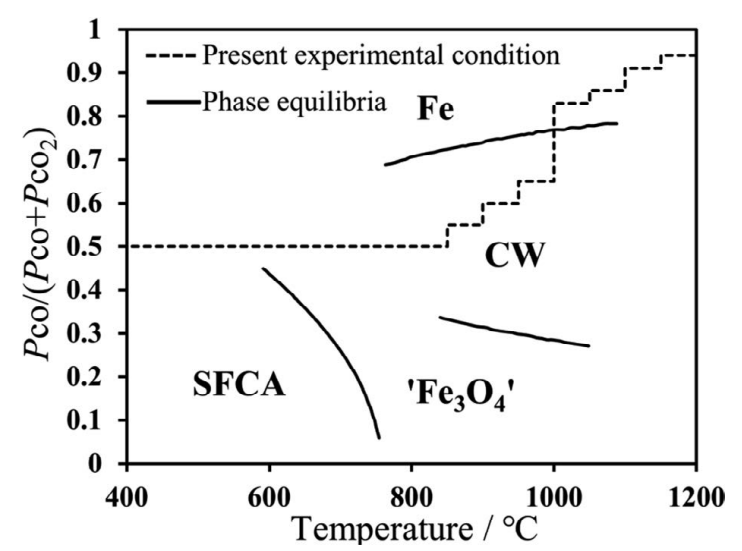

Fig. 15. Equilibrium relations among $\mathrm{SFCA}$, ' $\mathrm{Fe}_{3} \mathrm{O}_{4}$ ', $\mathrm{CW}, \mathrm{Fe}$ and $\mathrm{CO}-\mathrm{CO}_{2}$ gas mixture along with the gas composition change with temperature in the present experimental condition, shown by the dashed line.

around it. As shown in Fig. 4(b), 'Acicular SFCA' have many fine pores around SFCA phases, which would allow the SFCA phases to contact to reducing gas directly. In contrast, as shown in Fig. 3(b), SFCA phases in 'Columnar SFCA' are closely covered with slag phase, which would be an obstacle to reducing gas penetration to SFCA and worsen its reducibility.

Now focus on $\mathrm{Fe}_{2} \mathrm{O}_{3}$ phase, which disappears at lower temperatures than SFCA; instead $\mathrm{Fe}_{3} \mathrm{O}_{4}$ appears. This indicates that $\mathrm{Fe}_{2} \mathrm{O}_{3}$ is reduced to $\mathrm{Fe}_{3} \mathrm{O}_{4}$. On the contrary, there are previous reports that SFCA is reduced to $\mathrm{Fe}_{3} \mathrm{O}_{4}$ containing gangue minerals (denoted as ' $\mathrm{Fe}_{3} \mathrm{O}_{4}$ ') but not to $\mathrm{CW} .{ }^{18,19)}$ The contradiction between the present and previous studies may be interpreted as follows: Figure 15 shows the equilibrium relations among $\mathrm{SFCA},{ }^{2} \mathrm{Fe}_{3} \mathrm{O}_{4}$ ', $\mathrm{CW}, \mathrm{Fe}$ and $\mathrm{CO}-\mathrm{CO}_{2}$ gas mixture along with the gas composition change with temperature in the present experimental condition, shown by the dashed line. The equilibrium relation between SFCA and ' $\mathrm{Fe}_{3} \mathrm{O}_{4}$ ' has been reported by Usui et $a l .{ }^{20)}$ and those between ' $\mathrm{Fe}_{3} \mathrm{O}_{4}$ ' and $\mathrm{CW}$ and between $\mathrm{CW}$ and $\mathrm{Fe}$ by Maeda et al. ${ }^{12)}$ Although the equilibrium phase diagram has not been completely established, it is possible to roughly estimate the temperature range of the stable region for ' $\mathrm{Fe}_{3} \mathrm{O}_{4}$ ' phase. The stable region is not large on the dashed line, and thus ' $\mathrm{Fe}_{3} \mathrm{O}_{4}$ ' would exist only for a short time during the reduction process from SFCA to Fe. That is why the diffraction peaks due to ' $\mathrm{Fe}_{3} \mathrm{O}_{4}$ ' reduced from SFCA have not been observed in this study.

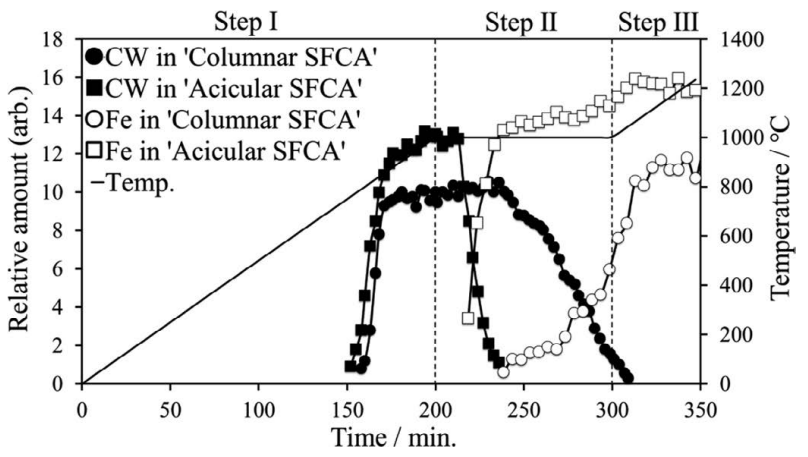

Fig. 16. Changes with time in the relative amounts of $\mathrm{CW}$ and $\mathrm{Fe}$ in 'Columnar SFCA' and 'Acicular SFCA', together with the temperature history.

\subsection{Reduction from $\mathrm{CW}$ to $\mathrm{Fe}$}

Figure 16 shows the change with time in the relative amounts of $\mathrm{CW}$ and $\mathrm{Fe}$ in 'Columnar SFCA' and 'Acicular SFCA', together with the temperature history. Fe phase appears almost as soon as CW phase starts to decrease, which indicates that $\mathrm{Fe}$ is reduced form $\mathrm{CW}$. It can also be seen that CW starts to decrease at $236 \mathrm{~min}$ in Step II for 'Columnar SFCA' and at $213 \mathrm{~min}$ for 'Acicular SFCA'. This suggests that $\mathrm{CW}$ in 'Acicular SFCA' has better reducibility than that in 'Columnar SFCA'. As shown in Fig. 10 , CW phase originating from 'Columnar SFCA' is still surrounded by slag at $1000^{\circ} \mathrm{C}$. On the other hand, some fine pores still remain around $\mathrm{CW}$ phases originating from 'Acicular SFCA' even after SFCA is reduced to CW, as shown in Fig. 11. This may be the main reason that $\mathrm{CW}$ in 'Acicular SFCA' has better reducibility than that in 'Columnar SFCA'. Taking a close look at the CW phases, it can be seen that some parts of CW reduced from SFCA is surrounded by 'silicate'. This would be an obstacle to reducing gas penetration to $\mathrm{CW}$ and worsen its reducibility. However, comparing to $\mathrm{CW}$ phases in 'Columnar SFCA', CW phases in 'Acicular SFCA' surrounded by 'silicate' phases still have an advantage in reducibility: As mentioned in 3.1, columnar SFCA phases typically have a size of $60 \mu \mathrm{m}$ in major axis $\times 10 \mu \mathrm{m}$ in minor axis while acicular SFCA phases typically have a size of $10 \mu \mathrm{m}$ in major axis $\times 0.5$ $\mu \mathrm{m}$ in minor axis. The penetration route through slag phase to reach the center of the $\mathrm{CW}$ phase is shorter in acicular $\mathrm{CW}$ phases than that in columnar $\mathrm{CW}$ phases. In general, the reducibility of $\mathrm{CW}$ in 'Acicular SFCA' is better than that in 'Columnar SFCA' for the two reasons above-mentioned. To the best of the authors' knowledge, there are no reports about the reducibility of acicular-SFCA-origin $\mathrm{CW}$ to $\mathrm{Fe}$ from the perspective of the morphology of SFCA.

\subsection{Effect of Hydrogen Additions on Reductions from SFCA to $\mathrm{CW}$ and from $\mathrm{CW}$ to $\mathrm{Fe}$}

Figure 17 compares the changes with time in the relative amounts of $\mathrm{CW}$ and $\mathrm{Fe}$ in 'Acicular SFCA' obtained in experiments with and without hydrogen additions, together with the temperature history. For both reduction experiments, $\mathrm{CW}$ appears around $750^{\circ} \mathrm{C}$, i.e., at $150 \mathrm{~min}$, and $\mathrm{Fe}$ appears almost as soon as $\mathrm{CW}$ starts to disappear, which indicates that $\mathrm{Fe}$ is reduced form $\mathrm{CW}$. CW starts to decrease at $213 \mathrm{~min}$ in Step II in case of no hydrogen additions, while CW starts to decrease 5 min earlier than in case of hydrogen 


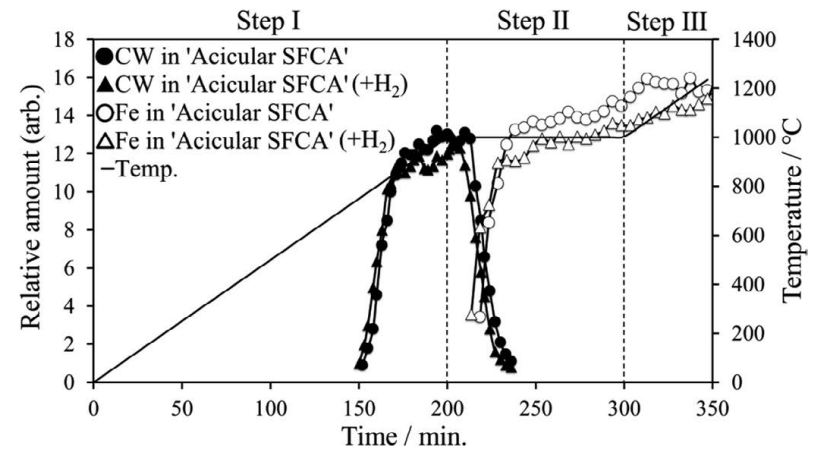

Fig. 17. Changes with time in the relative amounts of $\mathrm{CW}$ and $\mathrm{Fe}$ in 'Acicular SFCA' obtained in experiments with and without hydrogen additions, together with the temperature history.

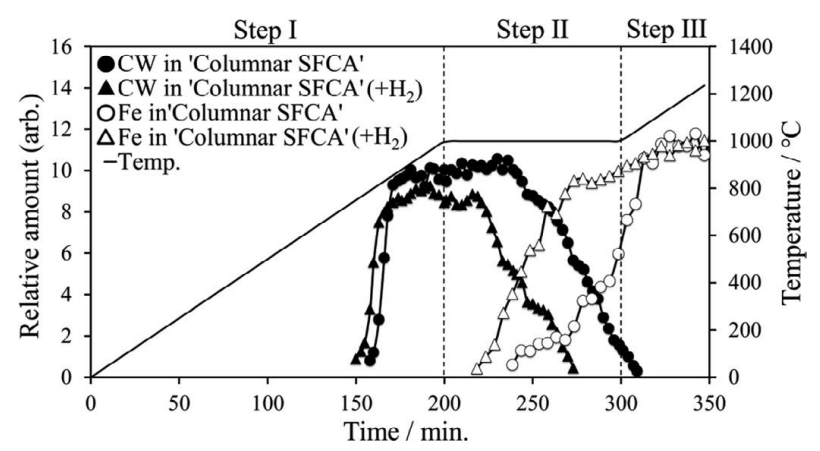

Fig. 18. Changes with time in the relative amounts of $\mathrm{CW}$ and $\mathrm{Fe}$ in 'Columnar SFCA' obtained in experiments with and without hydrogen additions, together with the temperature history.

additions. From these results, there is no effect of hydrogen addition on the reduction from SFCA to $\mathrm{CW}$ around $750^{\circ} \mathrm{C}$; however, hydrogen can slightly promote the reduction of $\mathrm{CW}$ in 'Acicular SFCA' at $1000^{\circ} \mathrm{C}$. It is commonly known that chemical reaction is rate controlling step at lower temperatures and the diffusion of gas in pores is rate controlling step at higher temperatures. In the present study, hydrogen addition has no effect on the CW generation from SFCA probably because the chemical reaction is rate controlling step around $750^{\circ} \mathrm{C}$; the effect of hydrogen addition can be seen on the $\mathrm{Fe}$ generation from $\mathrm{CW}$ because the diffusion in the pores is rate controlling step at $1000^{\circ} \mathrm{C}$.

Figure 18 compares the changes with time in the relative amounts of $\mathrm{CW}$ and $\mathrm{Fe}$ in 'Columnar SFCA' obtained in experiments with and without hydrogen additions, together with the temperature history. In case of no hydrogen additions, $\mathrm{CW}$ phase appears at $789^{\circ} \mathrm{C}$, i.e., at $158 \mathrm{~min}$ and starts to decrease at $236 \mathrm{~min}$ in Step II. In contrast, in case of hydrogen additions, $\mathrm{CW}$ phase appears at $750^{\circ} \mathrm{C}$, i.e., at $150 \mathrm{~min}$ and starts to disappear about $20 \mathrm{~min}$ earlier than in case of no hydrogen additions. These results indicate that hydrogen additions can promote the reduction of $\mathrm{CW}$ in 'Columnar SFCA' at $1000^{\circ} \mathrm{C}$ more effectively than in 'Acicular SFCA'. This difference would be explained as follows: $\mathrm{CW}$ in 'Columnar SFCA' is covered with slag phase, and hydrogen can diffuse through slag phase much faster than carbon monoxide, particularly at higher temperatures. On the other hand, CW in 'Acicular SFCA' has many fine pores around them, and the diffusion rate of carbon monoxide through the pores would be comparable to that of hydrogen.

\section{Conclusions}

High-temperature X-ray diffraction analysis has been applied to 'Columnar SFCA' and 'Acicular SFCA' to evaluate the reducibilities of the samples in $\mathrm{CO}-\mathrm{CO}_{2}-\mathrm{He}$ with and without hydrogen additions in the temperature history simulating a blast furnace condition.

The findings and conclusions obtained are summarized as follows:

(1) SFCA and CW phases in 'Acicular SFCA' have better reducibilities than those in 'Columnar SFCA'. This would be because SFCA phases in 'Acicular SFCA' have fine pores around them, which allow SFCA phases to contact to reducing gas directly. Fine pores have also been observed around $\mathrm{CW}$ in the samples after reduced to $\mathrm{CW}$.

(2) ${ }^{2} \mathrm{Fe}_{3} \mathrm{O}_{4}$ ' phase reduced from SFCA has not been observed in this study, probably because $\mathrm{Fe}_{3} \mathrm{O}_{4}$ could be thermodynamically stable only for a short time during the present reduction process.

(3) Hydrogen additions can promote reduction of both 'Columnar SFCA' and 'Acicular SFCA', and this effect is more significant on 'Columnar SFCA'. In particular, hydrogen addition promotes reduction from $\mathrm{CW}$ to $\mathrm{Fe}$ at $1000^{\circ} \mathrm{C}$ more effectively than that from SFCA to $\mathrm{CW}$ at lower temperatures.

\section{Acknowledgement}

The present work was carried out as a part of COURSE50 project. The authors are thankful to the New Energy and Industrial Technology Development Organization (NEDO) and the Japan Iron and Steel Federation (JISF) for their financial support.

\section{REFERENCES}

1) K. Sato, S. Suzuki, Y. Sawamura and K. Ono: Tetsu-to-Hagané, 68 (1982), 2215.

2) M. Sasaki and Y. Hida: Tetsu-to-Hagané, 68 (1982), 563.

3) T. Maeda and Y. Ono: Trans. Iron Steel Inst. Jpn., 25 (1985), 1191.

4) Y. Yamaoka, H. Hotta and S. Kajikawa: Tetsu-to-Hagané, 66 (1980), 1850 .

5) K. Mori, R. Hidaka and Y. Kawai: Tetsu-to-Hagané, 66 (1980), 1287.

6) H. Kokubu, A. Sasaki, S. Taguchi and N. Tsuchiya: Tetsu-to-Hagané, 68 (1982), 2338.

7) B. Cai, T. Watanabe, C. Kamijo, K. Sunahara, M. Susa and M. Hayashi: ISIJ Int., 57 (2017), 681.

8) N. Sakamoto, H. Fukuyo, Y. Iwata and T. Miyashita: Tetsu-toHagané, 70 (1984), 504.

9) T. Maeda and Y. Ono: Tetsu-to-Hagané, 72 (1986), 775.

10) T. Maeda, T. Furue, T. Murayama and Y. Ono: Tetsu-to-Hagané, 68 (1982), S736.

11) Y. Hida, K. Ito, J. Okazaki, M. Sasaki and Y. Umezu: Tetsu-toHagané, 68 (1982), 2166.

12) T. Maeda and Y. Ono: Tetsu-to-Hagané, 75 (1989), 416.

13) K. Inoue and T. Ikeda: Tetsu-to-Hagané, 68 (1982), 2190.

14) T. R. C. Patrick and M. I. Pownceby: Metall. Mater. Trans. B, 33B (2002), 79.

15) K. Sugiyama, A. Monkawa and T. Sugiyama: ISIJ Int., 45 (2005), 560.

16) N. A. S. Webster, M. I. Pownceby, I. C. Madsen and J. A. Kimpton: ISIJ Int., 53 (2013), 774.

17) W. G. Mumme, J. M. F. Clout and R. W. Gable: N. Jahrb. Mineral. Abh., 173 (1998), 93.

18) I. Shigaki, M. Sawada, J. M. Maekawa and K. Narita: Tetsu-toHagané, 68 (1982), 1513.

19) T. Maeda and Y. Ono: Tetsu-to-Hagané, 75 (1989), 416.

20) T. Usui, H. Kawabata, T. Fujimori, I. Fukuda and Z. Morita: Tetsuto-Hagané, 78 (1992), 982. 